\title{
Management of COVID-19 infection during pregnancy
}

\author{
J A V S Jayalatha, M I F Ifla ${ }^{\mathrm{b}}, \mathrm{S}$ K Chandrasinghe ${ }^{\mathrm{c}}$
}

\section{Introduction}

"COVID-19" came into our lives in November 2019, and has since created havoc around the globe. This infection is caused by the SARS-CoV-2 virus (severe acute respiratory syndrome coronavirus 2), which is a single chain, enveloped RNA virus ${ }^{1}$. The index case was reported on $17^{\text {th }}$ November 2019 from Hubei province, China, and it is believed to be of animal origin². Thereafter, the outbreak of COVID-19 infection has rapidly spread worldwide causing significant morbidity and mortality, including among pregnant mothers.

This was named as "COVID-19" by the WHO (World Health Organization) on $11^{\text {th }}$ February 2020 and declared as a global pandemic on $11^{\text {th }}$ March $2020^{2}$. More than 2.4 billion cases have been reported so far, with nearly 5 million deaths. The pandemic has affected countless more lives as relatives and friends of those who were infected. The economic and psychological impact of the many lockdowns and new health regulations is seen even today.

In Sri Lanka, more than 530,000 people have been infected and nearly 13,700 have died, including 56 maternal deaths. The impact of COVID-19 infection on pregnancy and the fetus has been evaluated worldwide, and management guidelines have been issued by leading organizations including RCOG (Royal College of Obstetricians and Gynaecologists), ACOG (American College of Obstetricians and Gynaecologists) and FIGO (International Federation of Gynaecology and Obstetrics) $)^{3,4,5}$. However, there is no well-established data on management of COVID-19 infection during pregnancy, since it is a new infection. Initially it was believed that pregnancy conferred a higher risk of disease morbidity and mortality, but currently, CDC (Center for Disease Control in USA) states that pregnancy has no additional risk of disease infectivity compared to the non-pregnant population ${ }^{6}$.

\section{Disease transmission}

COVID-19 infection is transmitted via respiratory droplets exhaled by infected patients through direct contact or through contaminated surfaces. Vertical transmission from mother to baby is a rare event and it will not depend on mode of delivery, delayed cord clamping or mode of baby feeding ${ }^{7,8}$.

\section{Symptoms and signs}

Symptoms and signs of COVID-19 during pregnancy are not different from non-pregnant patients (Table 1).

\section{Sri Lanka Journal of Obstetrics and Gynaecology 2021; 43: 128-137}

DOI: http://doi.org/10.4038/sljog.v43i3.8013

acting Obstetrician and Gynaecologist, Base Hospital, Udugama, Sri Lanka

b Registrar in Obstetrics and Gynaecology, Castle Street Hospital for Women, Colombo, Sri Lanka

c Registrar in Obstetrics and Gynaecology, De Soysa Maternity Hospital, Colombo, Sri Lanka.

Correspondence: JAVSJ, e-mail: sharadajayalath@yahoo.com

https://orcid.org/0000-0003-4100-0384

Received $1^{\text {st }}$ November 2021

Accepted $3^{\text {rd }}$ November 2021

This is an open-access article distributed under the terms of the Creative Commons Attribution 4.0 International License, which permits unrestricted use, distribution and reproduction in any medium provided the original author and source are credited. 
More than $75 \%$ of the patients are asymptomatic and only $15-20 \%$ of patients present with symptoms ${ }^{9}$. Among the symptomatic patients, majority have mild symptoms, less than $5 \%$ will have the severe disease requiring ICU admissions and less than $1 \%$ require invasive ventilatory support ${ }^{9}$.

Majority of the symptomatic patients presented with cough (41\%), fever (40\%), shortness of breath (21\%) and tiredness ${ }^{10,11,12}$. Less common symptoms include sore throat, headache, diarrhea, loss of taste or smell, nausea / vomiting and rhinorrhea ${ }^{10,11,2}$. However, some of these symptoms are difficult to differentiate from symptoms due to normal physiological changes in pregnancy including physiological shortness of breath, nausea/vomiting and fatigue. Therefore, during the assessment of a pregnant mother more specific symptoms should be concerned.

Depending on the symptoms and signs, patients are categorized as asymptomatic, mild disease, moderate disease, severe disease and critical disease (Table 2).

Severe disease is mostly confined to the third trimester of the pregnancy ${ }^{9}$. Shortness of breath / difficulty in breathing, chest pain and confusion are the alarming symptoms of severe disease. Pregnant mothers with risk factors are more vulnerable to develop severe disease ${ }^{11}$. Risk factors for severe disease include obesity (BMI more than 25), age more than 35 years, BlackAsian origin, being on immunosuppressive drugs, working in healthcare or public facing occupations and presence of comorbidities like diabetes, hypertension, asthma, heart disease, chronic liver disease, chronic lung disease, chronic kidney disease, organ transplantation and malignancies ${ }^{11}$. However, compared to non-pregnant women, pregnant women are more likely to be admitted to the ICU (OR 1.62) and more likely to require intubation and mechanical ventilatory support $(\text { OR } 1.88)^{10}$.

Table 1. Symptoms of COVID-19 infection

\begin{tabular}{|l|l|}
\hline Common symptoms & Cough \\
& Shortness of breath \\
& Fever \\
& Tiredness \\
\hline Less common symptoms & Sore throat \\
& Headache \\
& Diarrhea \\
& Loss of taste or smell \\
& Nausea/vomiting \\
& Rhinorrhea \\
\hline Serious symptoms & Shortness of breath / difficulty in breathing \\
& Chest pain \\
& Confusion \\
\hline
\end{tabular}


Table 2. Categorization of COVID-19 infection

\begin{tabular}{|c|c|}
\hline Categorization & Symptoms and signs \\
\hline Asymptomatic & No clinical symptoms or signs \\
\hline Mild disease & $\begin{array}{l}\text { Mild symptoms present } \\
\text { No shortness of breath / dyspnoea } \\
\text { Chest Xray - normal }\end{array}$ \\
\hline Moderate disease & $\begin{array}{l}\text { Evidence of viral pneumonia present } \\
\text { Oxygen saturation } 90-94 \% \text { (with or without oxygen) } \\
\text { No increase of work of breath (WOB) } \\
\text { Respiratory rate }<30 / \text { min } \\
\text { Chest Xray involvement }<50 \% \\
\text { Vital parameters stable } \\
\mathrm{PaO}_{2} / \mathrm{FiO}_{2} \text { ratio }>300\end{array}$ \\
\hline Severe disease & $\begin{array}{l}\text { Evidence of severe viral pneumonia } \\
\text { Oxygen saturation }<90 \% \\
\text { Work of breath increased } \\
\text { Respiratory rate }>30 / \mathrm{min} \\
\text { Chest Xray involvement }>50 \% \\
\text { Vital parameters not stable } \\
\mathrm{PaO}_{2} / \mathrm{FiO}_{2} \text { ratio }>300\end{array}$ \\
\hline Critical disease & $\begin{array}{l}\text { Severe disease with a multi organ failure } \\
\text { ARDS, sepsis, septic shock, complications such as } \\
\text { pulmonary embolism and acute coronary syndrome }\end{array}$ \\
\hline
\end{tabular}

ARDS - Acute Respiratory Distress Syndrome

\section{Investigations and diagnosis}

\section{RT-PCR}

RT-PCR (reverse transcriptase polymerase chain reaction) test is the gold standard for diagnosis of COVID-19 infection in pregnancy ${ }^{13}$. The specificity of RT-PCR test is almost $100 \%$ and sensitivity is $70 \%{ }^{14}$. The patients who are suspected to have COVID-19 infection based on symptoms, should undergo RT-PCR test for SARS-CoV-2 RNA using nasopharyngeal $\mathrm{swab}^{13}$. If the initial test result is negative but with high suspicion of the disease, RT-PCR test should be repeated.

\section{RAT}

RAT (rapid antigen test) is used as a diagnostic test for COVID-19 infection in certain conditions when urgent diagnosis is required, and it also used as a screening test. It is also performed using a nasopharyngeal swab. The main advantage of the test is that it requires only 15-30 minutes to receive the results, whereas RT-PCR takes 48-72 hours. However, it has a low sensitivity and specificity compared to RT-PCR ${ }^{15}$. Recent meta-analysis has found that sensitivity and specificity of RAT for SARS-CoV-2 virus is $56.2 \%$ and $99.5 \%$ respectively ${ }^{16}$. Positive predictive value of a positive result of RAT test is high, and it is higher than RT-PCR ${ }^{15}$. 


\section{Chest Xray}

Chest Xray is particularly important in suspected cases of COVID pneumonia. Findings of chest Xray include patchy multi-focal opacities. However, chest Xray findings of COVID pneumonia can be seen only in advanced disease ${ }^{17}$. There is a clear indication of chest Xray in advanced disease, however risk/benefit ratio must be considered when it is being used in less severe cases.

\section{CT chest}

CT chest is considered the imaging method of choice in the diagnosis of COVID pneumonia ${ }^{18}$. This was widely used before the RT-PCR was freely available to diagnose COVID pneumonia. Sensitivity and specificity of CT chest are $97 \%$ and $25 \%$ respectively with positive predictive value of $65 \%{ }^{19}$. Characteristic CT findings help to diagnose COVID pneumonia, including bilateral, subpleural, patchy and multi-focal opacities with ground glass appearance and peripheral consolidation ${ }^{20,21}$. These features can be seen one to three weeks after the onset of infection ${ }^{17}$.

\section{USS chest}

Ultrasound scanning of chest can be used to diagnose COVID pneumonia in pregnancy ${ }^{18}$. It has high sensitivity $(>90 \%)$ and specificity $(>95 \%)^{22}$. Ultrasound findings of COVID pneumonia includes patchy distribution of interstitial artifactual signs, extended distribution of interstitial artifactual signs and small subpleural consolidation ${ }^{18}$.

\section{MED test}

MED (modified exertional desaturation) test is a bed site clinical test used to detect subclinical COVID pneumonia in patients who are not on oxygen therapy and whose oxygen saturation is more than $96 \%$. Patients resting oxygen saturation is measured. The patient is asked to sit and stand for 1minute and, then to rest for 30 seconds. Post exertional oxygen saturation is measured. Positive test result is indicative of subclinical COVID pneumonia.

\section{Treatment}

Asymptomatic patients and patients with mild symptoms can be managed in the home setting under the direct supervision of field health authority / $\mathrm{MOH}$ (Medical officer of health). Patients with moderate to severe disease and symptomatic high risk groups should be managed in a dedicated hospital setup (preferably at a specialized COVID-19 care center), with a multidisciplinary involvement including physician, intensivist, obstetrician and neonatologist. Most of the drugs used to treat the COVID-19 infection do not have a proven safety profile in pregnancy. Key management aspects of the treatment of COVID-19 infection during pregnancy are summarized in table 3.

\section{Oxygen therapy}

Physiological changes in the pregnancy are important to maintain fetal oxygenation, and thus oxygen therapy for patients with COVID-19 in pregnancy is challenging. WHO recommends to maintain oxygen saturation between $92-95 \%$ and $\mathrm{PaO}_{2}>70 \mathrm{mmHg}$ to minimize fetal hypoxia, and the RCOG recommendation is to maintain the oxygen saturation above $94 \%^{3,23}$. Prone ventilation is a well-accepted way to improve oxygenation, and according to available data, it is a safe option in pregnancy ${ }^{24}$.

\section{Steroid therapy}

RCOG recommends steroids (oral prednisolone $40 \mathrm{mg}$ once daily or IV hydrocortisone $80 \mathrm{mg}$ twice daily for 10 days or until discharge) if the patient has needed oxygen therapy ${ }^{3}$. Further, low dose dexamethasone therapy has proven benefit of reducing mortality in severe disease. It reduces mortality by $20 \%$ in the mothers who receive oxygen therapy and by $33 \%$ in the mothers who are ventilated (RECOVERY trial) ${ }^{25}$. Dexamethasone is categorized as a pregnancy category C drug according to UK-MEC (medical eligibility criteria) due to its fetal side effects. However, ACOG recommends the use of dexamethasone in the management of COVID-19 infection in pregnancy when indicated, especially in ICU patients who are mechanically ventilated ${ }^{4,26}$.

\section{Antibiotics}

Routine antibiotic administration is not recommended unless a superadded bacterial infection is suspected ${ }^{3}$.

\section{LDA}

LDA (low dose aspirin) is recommended to continue in patients with high risk of developing preeclampsia ${ }^{3}$. However, COVID-19 infection is associated with thrombocytopenia in some patients and in such patients, LDA should be discontinued ${ }^{3}$. 
Table 3. Management of COVID-19 infection

\begin{tabular}{|c|c|}
\hline Categorization & Management \\
\hline Asymptomatic & $\begin{array}{l}\text { Can be managed in the home setting } \\
\text { Observe for 10-14 days (supervised observation) } \\
\text { Look for alarming symptoms and signs ( } \mathrm{SpO}_{2}<96 \% \text { with or } \\
\text { without exertion, SOB, chest pain, altered mental status) } \\
\text { Monitor saturation, respiratory rate, temperature } \\
\text { Continue LDA (add if indicated) } \\
\text { Daily MED test } \\
\text { Supervised care via telecommunication / web-based communication }\end{array}$ \\
\hline Mild disease & $\begin{array}{l}\text { Can be managed in the home setting (POA }>28 \text { weeks with high } \\
\text { risk factors should be admitted and closely monitored) } \\
\text { Observe for } 10 \text { - } 14 \text { days (supervised observation) } \\
\text { Symptomatic management for mild symptoms (antipyretics, } \\
\text { antihistamines, bronchodilators) } \\
\text { Look for alarming symptoms and signs ( } \mathrm{SpO}_{2}<96 \% \text { with or without } \\
\text { exertion, SOB, chest pain, altered mental status) - if present need } \\
\text { urgent admission to hospital-based care } \\
\text { Monitor saturation, respiratory rate, pulse rate, temperature } \\
\text { Continue LDA (add if indicated) } \\
\text { Daily MED test } \\
\text { Supervised care via telecommunication / web-based communication }\end{array}$ \\
\hline Moderate disease & $\begin{array}{l}\text { Need hospital-based care (need isolation) } \\
\text { Close monitoring of vital signs and disease progression (may need } \\
\text { ICU admission, early intubation and mechanical ventilation if disease } \\
\text { progresses) } \\
\text { Monitor for development of multiorgan failure } \\
\text { Daily investigations (FBC, CRP, RFT, LFT, LDH) } \\
\text { Oxygen therapy and monitor oxygen saturation closely } \\
\text { Start triple therapy (LMWH, dexamethasone, antibiotics) and triple } \\
\text { maneuvers (oxygen therapy, cyclical proning, strict bed rest with } \\
\text { preoxygenation before exertion) } \\
\text { MDT care including physician, intensivist and obstetrician }\end{array}$ \\
\hline
\end{tabular}




\begin{tabular}{|c|c|}
\hline Categorization & Management \\
\hline Severe disease & $\begin{array}{l}\text { Need ICU care } \\
\text { Close monitoring of vital signs and disease progression } \\
\text { Monitor for development of multiorgan failure } \\
\text { Monitor investigations closely } \\
\text { Monitor IL-6 level } \\
\text { Continue triple therapy and triple maneuvers } \\
\text { MDT care including physician, intensivist, obstetrician and } \\
\text { neonatologist } \\
\text { Early intubation and mechanical ventilation } \\
\text { Consider Tocilizumab - if criteria fulfilled } \\
\text { Consider REGEN-COV } \\
\text { Consider termination of pregnancy if required }\end{array}$ \\
\hline Critical disease & $\begin{array}{l}\text { ICU care } \\
\text { Continue mechanical ventilation } \\
\text { Continue triple therapy and triple maneuvers } \\
\text { Continue close monitoring of vital signs, lab investigations and } \\
\text { disease progression } \\
\text { Continue MDT care } \\
\text { IV Tocilizumab (if criteria fulfilled) } \\
\text { Termination of pregnancy if required }\end{array}$ \\
\hline
\end{tabular}

SOB - shortness of breath, LDA - low dose aspirin, MED test - modified exertional desaturation test, ICU - intensive care unit, FBC - full blood count, CRP - C reactive protein, RFT - renal function tests, LFT - liver function tests, LDH lactate dehydrogenase, LMWH - low molecular weight heparin, IL-6 - interleukin 6, MDT - multi disciplinary team

\section{Thromboprophylaxis-LMWH}

COVID-19 infection is associated with increased risk of thromboembolic disease due to an excessive inflammatory reaction caused by the disease ${ }^{27}$. Pregnancy itself is considered as a hypercoagulable state due to the physiological changes which occur. Theoretically, pregnant mothers have an added risk of thromboembolic disease during the infection. Therefore, all pregnant mothers who are admitted due to COVID-19 infection should be assessed by VTE risk assessment tools ${ }^{3}$. RCOG recommends to administer VTE (venous thromboembolism) prophylaxis with LMWH (low molecular weight heparin) for 10 days or until discharge, for all pregnant mothers admitted with confirmed or suspected COVID-19 infection unless there is a contraindication ${ }^{3}$.

\section{Tocilizumab}

Tocilizumab is an Interleukin-6 inhibitor, and it is used to inhibit the inflammatory process caused by COVID-19 infection. Its safety in pregnancy and lactation is not well established. However, available observational studies have shown positive effect in reducing mechanical ventilation and death in nonpregnant women ${ }^{28}$. RCOG strongly recommends the use of Tocilizumab (400-800mg single IV infusion) if the CRP value is $75 \mathrm{mg} / \mathrm{l}$ or more or if the patient is admitted to ICUi-3. 


\section{REGEN-COV}

REGEN-COV is a combination of monoclonal antibodies - casirivimab and imdevimab. U.S. FDA (United States Food and Drug Administration) authorizes the use of REGEN-COV as a therapy for post exposure prophylaxis of COVID-19 infection, and to prevent severe disease in high risk groups ${ }^{29}$. RCOG strongly recommends the use of REGEN-COV (8g single IV infusion) in patients whose SARS-CoV-2 antibodies are negative ${ }^{3}$.

\section{Remdesivir}

Recently developed Remdesivir is a viral RNA polymerase inhibitor. Remdesivir has recently been approved by FDA for use in COVID-19 infection. However, well-established data on the use of Remdesivir in pregnancy is sparse. According to RCOG guidelines, its use is limited to patients who are not improving and those who are deteriorating ${ }^{3}$.

\section{Azithromycin}

Azithromycin is not recommended to use in pregnancy due to lack of proven benefit ${ }^{3}$.

\section{Hydroxychloroquine}

Hydroxychloroquine is not recommended to use in pregnancy due to lack of proven benefit ${ }^{3}$.

\section{Lopinavir/Ritonavir}

Lopinavir/Ritonavir is not recommended to use in pregnancy due to lack of proven benefit ${ }^{3}$.

\section{Maternal complications}

Complications of COVID-19 infection during pregnancy includes ARDS, respiratory failure, pneumonia, sepsis, septic shock, venous-thromboembolism, multiorgan failure and death. Estimated risk of COVID19 associated maternal mortality is $2.4 / 100,000^{30}$.

Further, increased risk of perinatal mental health disorders including maternal depression and anxiety has been identified ${ }^{3}$.

\section{Neonatal complications}

Available data do not suggest an increased risk of congenital anomalies, miscarriages or early pregnancy loss due to COVID-19 infection ${ }^{\mathrm{f}-1}$. However, there is an increased risk of preterm delivery (6\%), small for

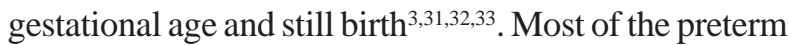
births are due to iatrogenic causes ${ }^{31,32,33}$. Recent metaanalysis found that there is an increased risk of premature rupture of membranes and fetal hypoperfusion $^{34}$.

\section{Vertical transmission}

There is no conclusive evidence on transplacental transmission of the disease, and it is thought to be rare.

\section{Delivery}

Vaginal delivery or caesarean section confers no additional risk on the disease progression of COVID19 infection. Therefore, mode of delivery during COVID-19 infection should be decided on an individualized basis depending on the obstetric indications and the severity of the disease. However, decision making should be based on MDT input including the obstetrician, physician and neonatologist. When iatrogenic preterm delivery is planned, antenatal corticosteroids for fetal lung maturation and $\mathrm{MgSO}_{4}$ for fetal neuroprotection should be administered.

Strict aseptic precautions should be adhered by the staff members who are involved in the delivery, and minimum number of staff members with full PPE (personal protective equipment) should be utilized. Emergency obstetric, anaesthetic and neonatal facilities should be readily available. CEFT (continuous electrical fetal monitoring) is not recommended routinely but recommended for all symptomatic patients ${ }^{3}$. Fetal blood sampling and scalp electrode are not contraindicated during COVID-19 infection. Delayed cord clamping and skin to skin contact of the baby should be allowed if the condition permits.

Water birth is not contraindicated for asymptomatic patients. However it is not recommended for symptomatic patients ${ }^{3}$.

\section{Postnatal care}

Routine postnatal care should be offered to all patients with COVID-19 infection ${ }^{3}$. Both mother and baby should be managed together unless there is a maternal or neonatal indication. 


\section{Breast feeding}

Breastfeeding should be encouraged since benefits of breastfeeding outweigh the potential risk of neonatal infection via breast milk. There is no proven evidence of transmitting the virus via breastmilk $\mathrm{k}^{35}$. There is a risk of transmitting the disease from mother to neonate via direct contact. However, this can be minimized by wearing a facemask and by good hand hygiene ${ }^{35}$. In case of expressed breastmilk, a breast pump is recommended with careful cleaning of the pump before and after each use ${ }^{35}$.

\section{Summary}

Majority of the pregnant mothers infected with COVID19 infection are asymptomatic. Among the symptomatic patients, majority have mild symptoms. Both these groups can be managed in a home-based setting. However, supervised observation and effective communication should be maintained to identify alarming symptoms and signs early. Patients with moderate to severe disease should be managed at hospital-based setting and close monitoring should be done to identify disease progression, development of multi organ failure and critical disease.

Early identification of alarming symptoms and signs, early hospitalization of the patients with moderate to severe disease, early intubation and mechanical ventilation and effective MDT management are the key steps in reducing maternal morbidity and mortality associated with COVID-19 infection.

\section{Author declarations}

Conflicts of interest: No conflicts of interest.

\section{References}

1. Corona virus Study Group of the International Committee on Taxonomy of Viruses. The species severe acute respiratory syndrome-related coronavirus: classifying 2019-nCoV and naming it SARS-CoV-2. Nature Microbiology. 2020; 5(4): 536-544.

2. WHO. Rolling updates on coronavirus disease (COVID-19). 2020. Accessed via https://www. who.int/emergencies/diseases/novel-coronavirus2019/events-as-they-happen

3. RCOG guideline on Coronavirus (COVID-19) infection in pregnancy. Published on 24th July 2020. Available at https://www.rcog.org.uk/ globalassets/documents/guidelines/2021-08-25coronavirus-covid-19-infection-in-pregnancyv14.pdf

4. ACOG practice advisory on Novel coronavirus 2019 (COVID-19) published on November 2020. Available at https://www.acog.org/clinical/clinicalguidance/practice-advisory/articles/2020/03/novelcoronavirus-2019

5. FIGO statement on Safe motherhood and COVID. March 2021 update. Available at https:// www.figo.org/safe-motherhood-and-covid-19march-2021-update

6. CDC. Investigating the impact of COVID-19 during pregnancy. Available at https://www. cdc.gov/coronavirus/2019-ncov/downloads/ cases-updates/covid-fs-Pregnancy.pdf

7. Walker KF, O'Donoghue K, Grace N, Dorling J, Comeau JL, Thornton JG. Maternal transmission of SARS-COV-2 to the neonate, and possible routes for such transmission: a systematic review and critical analysis. BJOG 2020; 127(11): 1324-1336

8. Jimenez IM, Lopez RS, Garcia RE, Rodriguez DLTI, Montes GJ, De la Cruz CML, et al. Umbilical cord clamping and skin-to-skin contact in deliveries from women positive for SARS-CoV2: a prospective observational study. BJOG 2021; 128(5):908-915

9. Vousden N, Bunch K, Morris E, et al. The incidence, characteristics and outcomes of pregnant women hospitalized with symptomatic and asymptomatic SARS-CoV-2 infection in the UK from March to September 2020: A national cohort study using the UK Obstetric Surveillance System (UKOSS). PLoS One 2021;16:e0251123

10. Allotey J, Stallings E, Bonet M, Yap M, Chattergee S, Kew T, Debenham L, et al. Clinical manifestations, risk factors, and maternal and perinatal outcomes of coronavirus disease 2019 in pregnancy: living systematic review and metaanalysis. BMJ 2020; 370: m3320.

11. Knight M, Bunch K, Vousden N, Morris E, Simpson $\mathrm{N}$, et al. Characteristics and outcomes of pregnant women admitted to hospital with confirmed SARSCoV-2 infection in UK: national population-based cohort study. BMJ 2020; 369: m2107.

12. Guan WJ, Ni ZY, Hu Y, Liang WH, Ou CQ, He JX, Liu L, Shan H, Lei C, Hui DSC, Du B, Li L, et al.; China medical treatment expert group for 
Covid-19. Clinical characteristics of coronavirus disease 2019 in China. New England Journal of Medicine 2020; 382(18):1708-1720.

13. Dashraath P, Wong JLJ, Lim MXK, Lim LM, Li S, Biswas A, Choolani M, Mattar C, Su LL. Coronavirus disease 2019 (COVID-19) pandemic and pregnancy. American Journal of Obstetrics and Gynecology 2020; 222(6): 521-531

14. Sethuraman N, Jeremiah SS, Ryo A. Interpreting diagnostic tests for SARS-CoV-2. JAMA. 2020; 323(22): 2249-2251.

15. Revised guideline on laboratory testing strategy for COVID 19, Ministry of Health Sri Lanka. Available at http://epid.gov.lk/web/images/pdf/Circulars/ Corona_virus/laboratory_testing_strategy.pdf

16. Coronavirus disease 2019 (COVID-19): interim guidance for antigen testing for SARS-CoV-2 CDC (2021) Revised April 13, 2021. Available at https:/ /www.cdc.gov/coronavirus/2019-ncov/lab/ resources/antigen-tests-guidelines.html

17. Shi H, Han X, Jiang N, Cao Y, Alwalid O, Gu J, et al. Radiological findings from 81 patients with COVID-19 pneumonia in Wuhan, China: a descriptive study. Lancet 2020; 20:425-434.

18. Inchingolo R, Smargiassi A, Moro F, Buonsenso D, Salvi S, Giacomo PD, Scoppettuolo G, Demi L, Soldati G, MD; Testa AC. The diagnosis of pneumonia in a pregnant woman with coronavirus disease 2019 using maternal lung ultrasound, July 2020. American Journal of Obstetrics \& Gynecology. 2020; 223(1): 9-11.

19. Ai T, Yang Z, Hou H, Zhan C, Chen C, et al. Correlation of Chest CT and RT-PCR Testing in Coronavirus Disease 2019 (COVID-19) in China: a Report of 1014 Cases. Radiology. 2020; 296(2): E32-40.

20. Salehi S, Abedi A, Balakrishnan S, Gholamrezanezhad A. Coronavirus disease 2019 (COVID19): a systematic review of imaging findings in 919 patients. American Journal Roentgenol. 2020; 215: 87-93.

21. Committee opinion no. 723: Guidelines for diagnostic imaging during pregnancy and lactation. Obstetrics and Gynecology 2017; 130: 933-934. Available at https://pubmed.ncbi. nlm.nih.gov/ 28937575/

22. Smargiassi A, Inchingolo R, Soldati G, Copetti R, Marchetti G, et al. The role of chest ultrasonography in the man- agement of respiratory diseases: document II. Multidisciplinary Respiratory Medicine. 2013; 8(1): 55.

23. Wu Y, Zhang C, Liu H, Duan C, Li C, Fan J, et al. Perinatal depressive and anxiety symptoms of pregnant women during the coronavirus disease 2019 outbreak in China. American Journal of Obstetrics and Gynecology. 2020; 223(2): 240.e1240.e9

24. Dennis AT, Hardy L, Leeton L. The prone position in healthy pregnant women and in women with preeclampsia - a pilot study. BMC Pregnancy Childbirth. 2018; 18 (1): 445

25. RECOVERY (Randomised Evaluation of COVid19 thERapY) trial Low-cost dexamethasone reduces death by up to one third in hospitalised patients with severe respiratory complications of COVID-19. 2020. https://www.recoverytrial.net/ files/recovery_dexamethasone_statement_ 160620_final.pdf

26. Saad AF, Chappell L, Saade GR, Pacheco LD. Corticosteroids in the management of pregnant patients with coronavirus disease (COVID-19). Obstetrics and Gynecology. 2020; 136(4): 823826.

27. Klok FA, Kruip MJHA, van der Meer NJM, Arbous MS, Gommers DAMPJ, et al. Incidence of thrombotic complications in critically ill ICU patients with COVID-19. Thromb Res. 2020; 191: 145-147.

28. Xu X, Han M, Li T, Sun W, Wang D, Fu B, et al. Effective treatment of severe COVID-19 patients with tocilizumab. PNAS 2020; 117: 10970-5.

29. U.S. Food and drug Administration (FDA). FDA authorizes REGEN-COV monoclonal antibody therapy for post-exposure prophylaxis (prevention) for COVID-19. Available at https:// www.fda.gov/drugs/drug-safety-and-availability/ fda-authorizes-regen-cov-monoclonal-antibodytherapy-post-exposure-prophylaxis-preventioncovid-19

30. Knight M, Bunch K. MBRRACE-UK : Saving Lives, Improving Mothers' Care. Rapid report 2021: Learning from SARS-CoV-2-related and associated maternal deaths in the UK June 2020-March 2021. Oxford, National Perinatal Epidemiology Unit, University of Oxford 2021. Available at https:// www.npeu.ox.ac.uk/assets/downloads/mbrraceuk/reports/MBRRACE-UK_Maternal_ Report_June_2021_-_FINAL_v10.pdf 
31. Yan J, Guo J, Fan C, Juan J, Yu X, Li J, et al. Coronavirus disease 2019 (COVID-19) in pregnant women: a report based on 116 cases. American Journal of Obstetrics and Gynecology. 2020; 223(1): 111.e1-111.e14

32. Di Mascio D, Khalil A, Saccone G, Rizzo G, Buca $\mathrm{D}$, Liberati $\mathrm{M}$, et al. Outcome of Coronavirus spectrum infections (SARS, MERS, COVID-19) during pregnancy: a systematic review and metaanalysis. American Journal of Obstetrics and Gynecology MFM. 2020; 2(2):100107.

33. Allotey J, Stallings E, Bonet M, et al. Clinical manifestations, risk factors, and maternal and perinatal outcomes of coronavirus disease 2019 in pregnancy: living systematic review and metaanalysis. BMJ. 2020; 370:m3320.

34. Dubey P, Reddy SY, Manuel S, Dwivedi AK. Maternal and neonatal characteristics and outcomes among COVID-19 infected women: an updated systematic review and meta-analysis. European Journal of Obstetrics Gynecology and Reprodive Biology. 2020; 252:490-501.

35. Davanzo R, Moro G, Sandri F, Agosti M, Moretti C, Mosca F. Breast feeding and coronavirus disease-2019: Ad interim indications of the Italian Society of Neonatology endorsed by the Union of European Neonatal \& Perinatal Societies. Maternal and Child Nutrition. 2020; 16(3):e13010. 